BMJ Open Diabetes Research \& Care

\title{
Comparison of a ready-to-use liquid glucagon injection administered by autoinjector to glucagon emergency kit for the symptomatic relief of severe hypoglycemia: two randomized crossover non-inferiority studies
}

\author{
Mark P Christiansen, ${ }^{1}$ Martin Cummins, ${ }^{2}$ Steven Prestrelski, ${ }^{2}$ Nicole C Close, ${ }^{3}$ \\ Anh Nguyen, ${ }^{2}$ Khaled Junaidi (iD ${ }^{2}$
}

To cite: Christiansen MP, Cummins M, Prestrelski S, et al. Comparison of a readyto-use liquid glucagon injection administered by autoinjector to glucagon emergency kit for the symptomatic relief of severe hypoglycemia: two randomized crossover non-inferiority studies. BMJ Open Diab Res Care 2021;9:e002137. doi:10.1136/ bmjdrc-2021-002137

\section{- Additional supplemental material is published online only. To view, please visit the journal online (http://dx.doi. org/10.1136/bmjdrc-2021- 002137).}

Received 13 January 2021 Accepted 25 August 2021

Check for updates

(c) Author(s) (or their employer(s)) 2021. Re-use permitted under CC BY-NC. No commercial re-use. See rights and permissions. Published by BMJ.

${ }^{1}$ Diablo Clinical Research, Walnut Creek, California, USA ${ }^{2}$ Clinical Development, Xeris Pharmaceuticals Inc, Chicago, Illinois, USA

${ }^{3}$ EmpiriStat Inc, Kitty Hawk, North Carolina, USA

Correspondence to Dr Khaled Junaidi; kjunaidi@xerispharma.com

\section{ABSTRACT}

Introduction To prevent medical sequelae of severe hypoglycemic emergencies, prompt and reliable rescue intervention is critically important. A ready-to-use, liquid stable glucagon, administered subcutaneously by glucagon autoinjector (GAl), Gvoke HypoPen (glucagon injection; Xeris Pharmaceuticals), was evaluated for rescue treatment of severe hypoglycemia.

Research design and methods Two phase III, randomized, controlled, blinded, non-inferiority crossover studies were conducted in 161 adults with type 1 diabetes to compare $1 \mathrm{mg}$ doses of GAl versus glucagon emergency kit (GEK) for treating insulin-induced severe hypoglycemia. Efficacy was evaluated as either a return of plasma glucose to $>70 \mathrm{mg} / \mathrm{dL}$ ( $3.9 \mathrm{mmol} / \mathrm{L}$ ) or increase $\geq 20 \mathrm{mg} /$ $\mathrm{dL}(1.1 \mathrm{mmol} / \mathrm{L})$ from a baseline glucose of $<50 \mathrm{mg} / \mathrm{dL}$ ( $2.9 \mathrm{mmol} / \mathrm{L})$, within $30 \mathrm{~min}$ of dosing.

Results For successful plasma glucose recovery within 30 min, treatment with GAl was non-inferior to GEK. Treatment with GAI was non-inferior to GEK for a plasma glucose $>70 \mathrm{mg} / \mathrm{dL}$ ( $3.9 \mathrm{mmol} / \mathrm{L})$ or neuroglycopenic symptom relief within $30 \mathrm{~min}$. From administration of glucagon, the mean time to achieve plasma glucose $>70 \mathrm{mg} / \mathrm{dL}(3.9 \mathrm{mmol} / \mathrm{L})$ or increase $\geq 20 \mathrm{mg} / \mathrm{dL}$ $(1.1 \mathrm{mmol} / \mathrm{L})$ was $13.8 \pm 5.6 \mathrm{~min}$ for GAl and $10.0 \pm 3.6 \mathrm{~min}$ for GEK. This mean time does not account for the significantly shorter $(p<0.0001)$ drug preparation and administration time for GAl $(27.3 \pm 19.7 \mathrm{~s})$ versus GEK (97.2 $\pm 45.1 \mathrm{~s})$. The incidence of treatment emergent adverse events was comparable in both groups. Conclusions A ready-to-use GAI was non-inferior to GEK, with a similar tolerability profile. GAl is an effective, safe, and well-tolerated rescue treatment for severe hypoglycemia and is a viable alternative to GEK. Trial registration numbers NCT02656069 and NCT03439072.

\section{INTRODUCTION}

Severe hypoglycemic events are mostly treated in a prehospital setting, ${ }^{1}$ and if not promptly and definitively treated with rapid-acting oral

\section{Significance of this study}

What is already known about this subject?

- Hypoglycemia is the major limiting factor in the optimal glycemic management of both type 1 and type 2 diabetes.

- Glucagon is indicated for the treatment of hypoglycemia in people unable or unwilling to consume carbohydrates by mouth. Current American Diabetes Association (ADA) standards recommend that glucagon should be prescribed for all individuals at increased risk of level 2 or 3 hypoglycemia so that glucagon is available should it be needed.

- Lyophilized glucagon emergency kits (GEKs) are available to treat severe hypoglycemia; however, they can be difficult to prepare because of manual reconstitution and dose preparation prior to injection. Successful rates for full dose glucagon delivery by users of GEK are low, reported in the range of $6 \%-31 \%$ in simulated emergency settings.

- Despite ADA guidelines, the poor usability of GEKs may contribute to the less than $50 \%$ of those with type 1 diabetes and less than $2.5 \%$ of those with type 2 diabetes having a filled glucagon prescription.

glucose ( $15 \mathrm{~g}$ of carbohydrate) or glucagon delivered via intravenous (IV), intramuscular, or subcutaneous (SC) administration, can progress to loss of consciousness, seizure, coma, or death. Currently, American Diabetes Association (ADA) recommends that glucagon should be prescribed, so it is available should it be needed for all individuals at increased risk of level 2 or 3 hypoglycemia. Level 2 hypoglycemia is defined as blood glucose $<54 \mathrm{mg} / \mathrm{dL}(3.0 \mathrm{mmol} / \mathrm{L})$ and level 3 hypoglycemia as a severe event characterized by altered mental and/or physical 


\section{Significance of this study}

What are the new findings?

- A ready-to-use glucagon autoinjector (GAl) was non-inferior to lyophilized powder glucagon emergency kit (GEK) for successful plasma glucose recovery within 30 min with a similar tolerability profile in adults with type 1 diabetes.

- Across both studies, the proportion of participants who achieved treatment efficacy was $98.7 \%$ in the GAl group and $100 \%$ in the GEK group.

- $99.4 \%$ of participants treated with GAl had a plasma glucose $>70 \mathrm{mg} / \mathrm{dL}(3.9 \mathrm{mmol} / \mathrm{L})$ or neuroglycopenic symptom relief within $30 \mathrm{~min}$ with a median time to any increase in plasma glucose of $102 \mathrm{~s}$.

- The mean time to achieve plasma glucose $>70 \mathrm{mg} / \mathrm{dL}(3.9 \mathrm{mmol} / \mathrm{L})$ or increase in plasma glucose $\geq 20 \mathrm{mg} / \mathrm{dL}$ ( $1.1 \mathrm{mmol} / \mathrm{L})$ was $13.8 \pm 5.6 \mathrm{~min}$ for $\mathrm{GAl}$ and $10.0 \pm 3.6 \mathrm{~min}$ for GEK. This mean time does not account for the statistically significant shorter drug preparation and administration time for GAl $(27.3 \pm 19.7 \mathrm{~s})$ versus GEK $(97.2 \pm 45.1 \mathrm{~s})(\mathrm{p}<0.0001)$.

- Hypoglycemia symptoms began to resolve as early as $5 \mathrm{~min}$ and total symptom relief occurred within $30 \mathrm{~min}$ after study glucagon administration.

How might these results change the focus of research or clinical practice?

- Prompt relief of neuroglycopenic symptoms are critical in the rescue of severe hypoglycemia emergencies.

- These two studies demonstrate that ready-to-use GAl supports the prompt and reliable administration of a full-dose of glucagon for treatment of severe hypoglycemia.

functioning that requires assistance from others. ${ }^{2}$ Caregivers, school personnel, and family members of these individuals should know where it is and when and how to administer it. Glucagon administration is not limited to healthcare professionals, particularly with the availability of intranasal and stable soluble glucagon available in autoinjector pens. ${ }^{2}$ While powdered glucagon emergency kits (GEKs) are available to treat severe hypoglycemia, they can be difficult to prepare because of a multistep manual reconstitution process, calibrating the pediatric dose requirement, and the ability to draw up the appropriate reconstituted glucagon volume prior to injection. These steps are error prone and may delay prompt and accurate administration of glucagon. ${ }^{3}$ Successful GEK delivery of a full dose of glucagon ranges from $6 \%$ to $31 \%{ }^{4-8}$ The poor usability of GEKs may contribute to the $<50 \%$ of those with type 1 diabetes and $<2.5 \%$ of those with type 2 diabetes having a filled glucagon prescription. ${ }^{9}$ Glucagon is often not available when needed, and even when accessible, it may be improperly prepared and administered, leading to a failed full dose of drug delivered.

A novel, ready-to-use, liquid stable glucagon formulation, Gvoke HypoPen, (glucagon injection; Xeris Pharmaceuticals) has been developed ${ }^{10}$ and is indicated for the treatment of severe hypoglycemia in pediatric and adult persons with diabetes (PWD) ages $>2$ years. ${ }^{11}$ GAI contains ready-to-use, liquid stable glucagon that is room temperature stable for up to 2 years and requires no reconstitution at the time of emergency. Similar to rescue pen products such as EpiPen (epinephrine injection, Mylan Inc), the GAI is single use only, has no visible needle, a needle guard that automatically locks after use, produces audible clicks when medication is delivered, and injects a full dose of medication. ${ }^{12}$ GAI provides a visual cue when the full drug dose has been successfully delivered. In two human factors studies with liquid stable glucagon administered in an autoinjector or in a prefilled syringe, 99\% of adolescent and adult, trained and untrained users, were able to successfully administer the full dose of glucagon, promptly and on first attempt during simulated emergency settings. ${ }^{812}$

We report results from two phase III studies conducted in North America comparing SC doses of GAI versus GEK (Glucagon; glucagon for injection; Lilly USA) for treating insulin-induced severe hypoglycemia in adults with type 1 diabetes.

\section{RESEARCH DESIGN AND METHODS}

Two phase III, randomized, controlled, blinded, noninferiority crossover studies were conducted in 161 adults with type 1 diabetes to compare $1 \mathrm{mg}$ doses of GAI versus GEK for the treatment of insulin-induced severe hypoglycemia. The 505(b) (2) regulatory pathway was followed for the development program of the liquid stable glucagon that required efficacy and safety comparisons with the current Reference Listed Drug, Lilly GEK, which is approved for the treatment of severe hypoglycemia. The primary objective of each study was to demonstrate the non-inferiority of GAI to GEK to achieve successful plasma glucose recovery, from a state of insulin-induced severe hypoglycemia (plasma glucose $<50 \mathrm{mg} / \mathrm{dL}$ $(2.9 \mathrm{mmol} / \mathrm{L}))$. Efficacy was evaluated as either a return of plasma glucose to $>70 \mathrm{mg} / \mathrm{dL}(3.9 \mathrm{mmol} / \mathrm{L})$ or increase in plasma glucose $\geq 20 \mathrm{mg} / \mathrm{dL}(1.1 \mathrm{mmol} / \mathrm{L})$ from a baseline glucose $<50 \mathrm{mg} / \mathrm{dL}(2.9 \mathrm{mmol} / \mathrm{L})$, within $30 \mathrm{~min}$ of dosing. A failure for either treatment was recorded if plasma glucose remained $\leq 70 \mathrm{mg} / \mathrm{dL}(3.9 \mathrm{mmol} / \mathrm{L})$ or an increase $<20 \mathrm{mg} / \mathrm{dL}(1.1 \mathrm{mmol} / \mathrm{L})$ throughout the $0-30$ min period from study drug administration. Secondary objectives were to compare the glucose pharmacodynamics (PD), hypoglycemic symptom relief, glucagon pharmacokinetics (PK), drug preparation time, and the safety and tolerability of GAI versus GEK. XSGP-301 was a non-inferiority, randomized, controlled, double-blind, two-treatment, two-way crossover comparative efficacy and safety study in adult participants with type 1 diabetes. XSGP-303 was similar in design to XSGP301, except that it incorporated a single blind (only the participant was blinded to the treatment assignment), in order to better emulate a real-world setting, and evaluate glucagon preparation and administration by the caregiver. These two studies were conducted across 13 clinical research centers in North America. 
Participants included men and women aged 18-75 years with type 1 diabetes for $>24$ months; use of daily insulin $(<2.0 \mathrm{U} / \mathrm{kg}$ total insulin/day); an assigned correction factor for managing hyperglycemia; and a C-peptide level $<0.5 \mathrm{ng} / \mathrm{mL}$ at screening. Exclusion criteria included a glycated hemoglobin level $>9 \%$; body mass index $>40 \mathrm{~kg} /$ $\mathrm{m}^{2}$ (XSGP-303); any medical condition that could interfere with the conduct of the study; history of allergy or hypersensitivity to glucagon or glucagon-like products; and history of pheochromocytoma, insulinoma, and glycogen storage disease. Full protocol details are available at ClinicalTrials.gov.

Enrolled study participants were randomly assigned to one of two treatment groups in a crossover fashion using a block design stratified by clinic (group 1: GAI to GEK, group 2: GEK to GAI). Participants underwent two glucagon dosing visits, scheduled 7-28 days apart. Each participant was randomly assigned to receive either GAI $1 \mathrm{mg}$ SC or GEK $1 \mathrm{mg}$ SC during the initial insulin-induced hypoglycemia clamp procedure, and then received the other assigned glucagon preparation at the second scheduled clamp procedure. The study procedure consisted of inducing clinically important severe hypoglycemia (level 2$)^{2}$ by continuous IV administration of regular insulin diluted in normal saline. Each participant received the assigned study drug during the insulin-induced hypoglycemia clamp procedure (online supplemental figure 1). Each glucagon dosing visit was conducted after an overnight fast of at least 8 hours with a starting plasma baseline glucose between 75 and $115 \mathrm{mg} / \mathrm{dL}(4.2-6.4 \mathrm{mmol} / \mathrm{L})$. To achieve level 2 hypoglycemia, a combination of one or more IV bolus doses of insulin along with a continuous IV infusion of insulin was used to decrease plasma glucose to a target value $<50 \mathrm{mg} / \mathrm{dL}(2.9 \mathrm{mmol} / \mathrm{L})$. The continuous IV insulin infusion was stopped once plasma glucose was $<50 \mathrm{mg}$ / $\mathrm{dL}(2.9 \mathrm{mmol} / \mathrm{L})$. When confirmatory plasma glucose of $<50 \mathrm{mg} / \mathrm{dL}(2.9 \mathrm{mmol} / \mathrm{L})$ was obtained at least $5 \mathrm{~min}$ after the initial reading, then the participant received a SC injection of the assigned study drug to the upper arm, leg, or abdomen. Injection site was determined through randomization assignment via electronic data capture for each participant and remained fixed between treatment visits. Plasma glucose levels were monitored for a minimum of $90 \mathrm{~min}$ post dosing. Participants completed a questionnaire about symptoms of hypoglycemia during the hypoglycemia induction phase and at $45 \mathrm{~min}$ after treatment. All readings for plasma glucose levels were based on the average of two blood samples taken at each time point. After completion of both treatment visits, a follow-up visit was conducted 3-14 days later.

In XSGP-301, plasma PK glucagon levels were measured at treatment visits 1 and 2 with venous blood samples obtained at -5 and $0 \mathrm{~min}( \pm 2 \mathrm{~min})$ and at 10 , $20,30,45,60,90,120,180$, and $240 \mathrm{~min}( \pm 5 \mathrm{~min})$ post dose. Plasma PK glucagon levels were not measured in XSGP-303. Venous plasma PD glucose was measured via a rapid glucose analyzer (YSI 2900/2100, Yellow Springs
Instruments, Yellow Springs, Ohio, USA) and continuous glucose monitor (Dexcom G4, XSGP-303 only) before and during insulin-induced hypoglycemia clamp procedure, and at $-5,0$, and every $5 \mathrm{~min}$ post dose through $90 \mathrm{~min}( \pm 2 \mathrm{~min})$ in both studies. Additional PD measurements were measured at 120,150 , and $180 \mathrm{~min}( \pm 5 \mathrm{~min})$ post dose for XSGP-303.

Participants completed a hypoglycemia symptom questionnaire and injection site discomfort scales, and Draize scales $^{13}$ for erythema/edema were completed by investigators during and after each treatment visit. Symptoms of hypoglycemia were captured using a questionnaire that measured severity of symptoms, defined as neuroglycopenic symptoms (dizziness, blurred vision, difficulty in thinking, and faintness), autonomic symptoms (sweating, tremor, palpitations, and feelings of nervousness) and an overall assessment of hypoglycemia (yes/no - 'Do you currently feel hypoglycemic?'). For XSGP-303 only, participants also completed the Gold Scale for Hypoglycemia Awareness ${ }^{14}$ at the time of screening.

Drug preparation time was only evaluated in XSGP-303. Total preparation time was defined as the time required to inject the assigned glucagon preparation into the injection site from a decision to treat and was compared between the two treatment groups. Measurements were defined as the time between decision to dose by the investigator and time of end of injection (ie, receiving glucagon), and time needed by the study personnel to physically prepare/reconstitute the drug and complete the injection of the study drug.

\section{Statistical methodology}

For both studies, sample size calculation was based on an acceptance criterion for the sample mean of the treatment minus control group failure scores. XSGP-301 had a total of 80 participants and XSGP-303 had 81 participants. Monte Carlo simulations were performed using the acceptance criteria wherein XSGP-301 probabilities of GAI acceptance of over $90 \%$ if the population failure rate of GAI and control were equal, and the rate of missing observations was within 15\%; and for XSGP-303 probabilities of GAI acceptance of $88 \%$ if the population failure rate of GAI and control were within $2 \%$, and the rate of missing observations was within $5 \%$. Simulations were conducted using $\mathrm{R}$ software. ${ }^{15}$

The outcome for treatment success was defined as either a return of plasma glucose to $>70 \mathrm{mg} / \mathrm{dL}$ $(3.9 \mathrm{mmol} / \mathrm{L})$ or increase in plasma glucose $\geq 20 \mathrm{mg} /$ dL $(1.1 \mathrm{mmol} / \mathrm{L})$ from baseline glucose within $30 \mathrm{~min}$ of receiving glucagon. Treatment success was evaluated by a composite failure score defined by the event when plasma glucose of a participant remains $\leq 70 \mathrm{mg} / \mathrm{dL}$ $(3.9 \mathrm{mmol} / \mathrm{L})$ without a $20 \mathrm{mg} / \mathrm{dL}(1.1 \mathrm{mmol} / \mathrm{L})$ increase from baseline throughout the 0 to $30 \mathrm{~min}$ period after receiving glucagon. A failure score of 1 corresponded to an observed failure. A failure score of 0 corresponded to successful plasma glucose recovery. A failure score of 0.2 was assigned for instances of missing GAI treatment 
outcomes, and 0.1 was assigned for instances of missing GEK treatment outcomes.

The intent-to-treat (ITT) population was all participants randomized to study drug and analyzed based on planned treatment sequence for each participant. The safety population was all randomized participants who received at least 1 dose of study drug. The per-protocol (PP) population was all participants who received at least 1 dose of study drug (XSGP-303 required both treatments be received for inclusion in this population) and completed the study without major protocol deviations. For XSGP-301, a modified intent-to-treat (mITT) population was defined as all participants in the ITT population who received at least one dose of study drug. The mITT, $\mathrm{PP}$, and safety populations were analyzed based on the actual treatment received by each participant.

The sample mean and $\mathrm{SE}$ of the difference in composite failure scores between GAI (treatment) and GEK (reference) from each participant was calculated. Non-inferiority was assessed based on a one-sided confidence bound derived via Monte Carlo simulation with an $\alpha$ of 0.025 , and a non-inferiority margin of $0.1(\Delta=0.1)$. Missing data were imputed for the primary efficacy analysis and the PP population was used. Secondary outcomes were assessed descriptively and inferentially. Key secondary outcomes included time to first plasma glucose measurement $>70 \mathrm{mg} / \mathrm{dL}$, time to first reporting of 'No' hypoglycemia, time to minimum Hypoglycemia Questionnaire score, dose preparation time and key PD parameters: $\mathrm{AUC}, \mathrm{C}_{\max }$, and $\mathrm{T}_{\max }$.

Inferential analysis of secondary endpoints was performed using a mixed model with treatment, period, and sequence as fixed factors and participant as the random repeated factor. The unstructured covariance matrix was chosen. If non-normality was observed and could not be corrected with a log transformation, a nonparametric Kruskal-Wallis test was applied and conducted for each treatment period separately. For XSGP-301, time to minimum Hypoglycemia Questionnaire scores and hypoglycemia symptom relief was evaluated by comparing HRs of each treatment group using the log rank test. Statistical analyses were performed using SAS V.9.1.3 for Windows (SAS Institute, Cary, North Carolina, USA). Each study was individually analyzed and reported. An Integrated Summary of Safety and Integrated Summary of Efficacy were conducted for the regulatory package. For purposes of summarization, aggregate data are presented descriptively in the results tables.

\section{RESULTS}

XSGP-301 randomized 80 participants at seven sites in North America between March and August 2017, and $78(97.5 \%)$ completed the study (online supplemental figure 2). XSGP-303 randomized 81 participants at six sites in North America between January and April 2018, and $75(92.6 \%)$ completed the study (online supplemental figure 3). Baseline characteristics were similar between studies (table 1).

\section{XSGP-301}

In XSGP-301, mean plasma glucose at the time of glucagon administration was $44.8 \mathrm{mg} / \mathrm{dL}(2.5 \mathrm{mmol} / \mathrm{L})$ and $45.2 \mathrm{mg} / \mathrm{dL}(2.5 \mathrm{mmol} / \mathrm{L})$ for GAI and GEK, respectively. Seventy-six $(97.4 \%)$ and $79(100 \%)$ participants achieved a plasma glucose value $>70 \mathrm{mg} / \mathrm{dL}$ $(3.9 \mathrm{mmol} / \mathrm{L})$ or increase in plasma glucose $\geq 20 \mathrm{mg} / \mathrm{dL}$ $(1.1 \mathrm{mmol} / \mathrm{L})$ from baseline after administration of GAI and GEK, respectively. GAI satisfied the non-inferiority criterion to GEK based on analyses of failure scores for both the ITT and PP (online supplemental table 2). All participants exhibited a sustained elevation in plasma glucose levels $>70 \mathrm{mg} / \mathrm{dL}(3.9 \mathrm{mmol} / \mathrm{L})$ from 0 to $90 \mathrm{~min}$ post injection with both GAI and GEK, without need for an additional dose of glucagon or other medical intervention (table 2). Mean hypoglycemia questionnaire scores (neuroglycopenic, autonomic, and total) were similar between GAI and GEK at all time points assessed post administration (online supplemental figure 4). As plasma glucose levels increased, mean hypoglycemia symptom scores among those with symptoms decreased for both GAI and GEK. Hypoglycemia symptoms began to resolve as early as $5 \mathrm{~min}$ and total symptom relief occurred within 30 min after study glucagon administration (figure 1). Resolution of hypoglycemia symptoms was similar between the groups, and in almost all cases, it preceded the return of documented euglycemia. Time to minimum autonomic, neuroglycopenic, and total hypoglycemia symptom scores were similar between GAI and GEK from 0 to $90 \mathrm{~min}$ post study drug injection (table 2).

The time to minimum hypoglycemia score was calculated for the autonomic and neuroglycopenic symptom subscales as the difference (in min) between the actual time when the minimum number of each of the two scores was observed and the injection time. Time from glucagon administration to global resolution of hypoglycemia symptoms, time to minimum hypoglycemia questionnaire score for the total score, and time to minimum autonomic and neuroglycopenic symptom scores was similar between treatment groups. Most participants with symptoms in both treatment groups exhibited symptomatic relief (ie, were no longer answering 'Yes' to the hypoglycemia feeling question) by $20-25 \mathrm{~min}$ post glucagon administration. Overall, no significant differences $(p>0.05, \log$ rank test) were noted between treatments. GAI and GEK were comparable for hypoglycemia symptom relief (table 2 , figure 1 ).

In general, participants in the GEK treatment group achieved plasma glucose recovery $>70 \mathrm{mg} / \mathrm{dL}$ $(3.9 \mathrm{mmol} / \mathrm{L})$ earlier than participants in the GAI treatment group (GEK: mean of $14.2 \mathrm{~min}$ (SD: 4.26), GAI: 19.9 min (8.51)), from time of study drug administration (table 2). These differences were not clinically meaningful, given that both the time course and extent of 
Table 1 Baseline demographics by study and pooled overall - all randomized participants

\begin{tabular}{|c|c|c|c|c|}
\hline Parameter & Category/statistic & XSGP-301 $(n=80)$ & XSGP-303 $(n=81)$ & Overall $(n=161)$ \\
\hline \multirow[t]{3}{*}{ Age (years) } & $\mathrm{n}$ & 80 & 81 & 161 \\
\hline & Mean $\pm S D$ & $43.6 \pm 15.25$ & $38.2 \pm 14.62$ & $40.9 \pm 15.13$ \\
\hline & Range & $18-74$ & $18-72$ & $18-74$ \\
\hline \multirow[t]{2}{*}{ Sex, n (\%) } & Male & $44(55.0)$ & $44(54.3)$ & $88(54.7)$ \\
\hline & Female & $36(45.0)$ & $37(45.7)$ & $73(45.3)$ \\
\hline \multirow[t]{7}{*}{ Race, n (\%) } & White & $73(91.3)$ & $71(87.7)$ & $144(89.4)$ \\
\hline & Black or African-American & $4(5.0)$ & 0 & $4(2.5)$ \\
\hline & Asian & $1(1.3)$ & $6(7.4)$ & $7(4.3)$ \\
\hline & American Indian or Alaska Native & 0 & 0 & 0 \\
\hline & Native Hawaiian or other Pacific Islander & 0 & 0 & 0 \\
\hline & Multiple & $2(2.5)$ & $3(3.7)$ & $5(3.1)$ \\
\hline & Other & 0 & $1(1.2)$ & $1(0.6)$ \\
\hline \multirow[t]{2}{*}{ Ethnicity } & Hispanic or Latino & $6(7.5)$ & $6(7.4)$ & $12(7.5)$ \\
\hline & Non-Hispanic or Latino & $74(92.5)$ & $75(92.6)$ & $149(92.5)$ \\
\hline \multirow[t]{3}{*}{ Baseline BMI $\left(\mathrm{kg} / \mathrm{m}^{2}\right)$} & $\mathrm{n}$ & 80 & 79 & 159 \\
\hline & Mean $\pm S D$ & $28.01 \pm 6.206$ & $26.28 \pm 3.836$ & $27.15 \pm 5.222$ \\
\hline & Range & $19.3-60.2$ & $18.8-36.9$ & $18.8-60.2$ \\
\hline \multirow{3}{*}{$\begin{array}{l}\text { Duration of type } 1 \\
\text { diabetes (years) }\end{array}$} & $\mathrm{n}$ & 78 & 63 & 141 \\
\hline & Mean $\pm S D$ & $22.1 \pm 12.58$ & $20.3 \pm 10.32$ & $21.3 \pm 11.62$ \\
\hline & Range & $3-54$ & $3-52$ & $3-54$ \\
\hline
\end{tabular}

BMI, body mass index.

relief of symptomatic hypoglycemia was similar for GAI compared with GEK.

In a subgroup analysis by ethnicity/race (AfricanAmerican, Hispanic white, non-Hispanic white, and Other), mean plasma glucagon concentrations for the first 12 participants in each GAI subgroup showed minimal differences (online supplemental figure 5). GAI demonstrated successful restoration of normal plasma glucose levels within $30 \mathrm{~min}$ of drug administration from a state of insulin-induced severe hypoglycemia and was comparable with GEK for plasma glucose $\mathrm{C}_{\max }$, $\mathrm{T}_{\max }$, area under the curve (AUC), and plasma glucose concentration-by-time curves, which showed little separation between treatments (online supplemental table 1).

\section{XSGP-303}

In XSGP-303, mean plasma glucose at time of glucagon administration was $47.7 \mathrm{mg} / \mathrm{dL} \quad(2.6 \mathrm{mmol} / \mathrm{L})$ and $48.7 \mathrm{mg} / \mathrm{dL}(2.7 \mathrm{mmol} / \mathrm{L})$ for GAI and GEK, respectively. Seventy-six (100\%) and $79(100 \%)$ participants achieved a plasma glucose value $>70 \mathrm{mg} / \mathrm{dL}(3.9 \mathrm{mmol} / \mathrm{L})$ or increase in plasma glucose $\geq 20 \mathrm{mg} / \mathrm{dL}(1.1 \mathrm{mmol} / \mathrm{L})$ from baseline after administration of GAI and GEK, respectively. Thus, GAI satisfied the criterion for non-inferiority to GEK based on analyses of failure scores for both the ITT and PP (online supplemental table 2). All participants exhibited a sustained elevation in plasma glucose levels $>70 \mathrm{mg} / \mathrm{dL}$ $(3.9 \mathrm{mmol} / \mathrm{L})$ from 0 to $90 \mathrm{~min}$ post injection with both GAI and GEK, without need for an additional dose of glucagon or other medical intervention. Similar to XSGP-301, GAI was therapeutically equivalent to GEK in clinically meaningful effects and comparable in terms of PD endpoints: plasma glucose $\mathrm{C}_{\max }, \mathrm{T}_{\max }$, and AUC (online supplemental table 1). The mean time for plasma glucose recovery after administration of GAI was rapid, $12.5 \mathrm{~min}$ for a concentration $>70 \mathrm{mg} / \mathrm{dL}(3.9 \mathrm{mmol} / \mathrm{L})$, and $11.4 \mathrm{~min}$ for a $20 \mathrm{mg} /$ $\mathrm{dL}(1.1 \mathrm{mmol} / \mathrm{L})$ increase from baseline. From injection, a post hoc analysis demonstrated that the median time to first $10 \mathrm{mg} / \mathrm{dL}(0.6 \mathrm{mmol} / \mathrm{L})$ increase from hypoglycemic baseline with GAI was $7.2 \mathrm{~min}$.

GAI and GEK were comparable for hypoglycemia symptom relief (table 2). Time from glucagon administration to global resolution of hypoglycemia symptoms and time to minimum hypoglycemia questionnaire score for the total score as well as the autonomic and neuroglycopenic symptom scores were similar between groups (table 2 and online supplemental figure 4). Time to a plasma glucose concentration $>70 \mathrm{mg} / \mathrm{dL}(3.9 \mathrm{mmol} / \mathrm{L})$ was about $2.5 \mathrm{~min}$ faster from a decision to dose, and about $3.5 \mathrm{~min}$ faster from time of study drug injection, with GEK when compared with GAI. These differences had no impact on time to relief/resolution of hypoglycemia symptoms. For the overall assessment of hypoglycemia, the time to 'experiencing no hypoglycemia' based on decision to dose was significantly faster with GAI than with GEK (LS mean (SE) difference: -2.5 (1.04), 95\% CI -4.21 to -0.75 ); $\mathrm{p}=0.02$ (table 2 ). 
Table 2 Clinical outcomes by study and treatment

\begin{tabular}{|c|c|c|c|c|c|}
\hline \multirow[b]{2}{*}{ Outcome } & \multirow[b]{2}{*}{ Statistic } & \multicolumn{2}{|l|}{ XSGP-301* } & \multicolumn{2}{|l|}{ XSGP-303* } \\
\hline & & $\begin{array}{l}\text { GAl } 1 \mathrm{mg} \\
(\mathrm{n}=78)\end{array}$ & GEK $1 \mathrm{mg}(\mathrm{n}=79)$ & $\begin{array}{l}\text { GAl } 1 \mathrm{mg} \\
(\mathrm{n}=76)\end{array}$ & GEK 1 mg $(n=78)$ \\
\hline $\begin{array}{l}\text { Participants having plasma glucose } \\
\text { measurement }>70 \mathrm{mg} / \mathrm{dL} \text { ( } 3.9 \mathrm{mmol} / \mathrm{L}) \\
\text { within } 30 \mathrm{~min} \text { after receiving glucagon }\end{array}$ & n (\%) & 74 (94.9)† & 79 (100) & $76(100)$ & 78 (100) \\
\hline $\begin{array}{l}\text { Participants having plasma glucose } \\
\text { measurement increased } 20 \mathrm{mg} / \mathrm{dL} \\
(1.1 \mathrm{mmol} / \mathrm{L}) \text { within } 30 \mathrm{~min} \text { after receiving } \\
\text { glucagon }\end{array}$ & n (\%) & $76(97.4) \dagger$ & 79 (100) & $76(100)$ & 78 (100) \\
\hline $\begin{array}{l}\text { Participants having plasma glucose } \\
\text { measurement }>70 \mathrm{mg} / \mathrm{dL} \text { ( } 3.9 \mathrm{mmol} / \mathrm{L}) \text { or } \\
\text { neuroglycopenic symptom relief within } \\
30 \text { min after receiving glucagon }\end{array}$ & n (\%) & 77 (98.7) & 79 (100) & $76(100)$ & 78 (100) \\
\hline \multirow{3}{*}{$\begin{array}{l}\text { Time }(\mathrm{min}) \text { to first plasma glucose } \\
\text { measurement }>70 \mathrm{mg} / \mathrm{dL}(3.9 \mathrm{mmol} / \mathrm{L}) \\
\text { after receiving glucagon } \ddagger\end{array}$} & $\mathrm{n}$ & 78 & 79 & 76 & 78 \\
\hline & Mean \pm SD & $19.86 \pm 8.508$ & $14.23 \pm 4.258$ & $12.17 \pm 3.604$ & $8.58 \pm 2.026$ \\
\hline & $P$ value & & $\begin{array}{l}\text { Period 1: } 0.0001 \S \\
\text { Period 2: } 0.0004 \S\end{array}$ & & $\begin{array}{l}\text { Period } 1:<0.0001 \S \\
\text { Period } 2:<0.0001 \S\end{array}$ \\
\hline \multirow{3}{*}{$\begin{array}{l}\text { Time (min) to first reporting of 'no' } \\
\text { hypoglycemia after receiving glucagon } \neq\end{array}$} & $\mathrm{n}$ & 76 & 79 & 76 & 78 \\
\hline & Mean $\pm S D$ & $16.8 \pm 10.68$ & $15.7 \pm 8.30$ & $11.6 \pm 6.45$ & $13.1 \pm 7.86$ \\
\hline & $P$ value & & 0.368 & & 0.156 \\
\hline \multirow{3}{*}{$\begin{array}{l}\text { Time (min) to first reporting of 'no' } \\
\text { hypoglycemia after decision to dose }\end{array}$} & $\mathrm{n}$ & NR & NR & 76 & 78 \\
\hline & Mean $\pm S D$ & & & $12.69 \pm 6.446$ & $15.26 \pm 8.008$ \\
\hline & $P$ value & & & & 0.020 \\
\hline \multirow{3}{*}{$\begin{array}{l}\text { Time (min) to minimum hypoglycemia } \\
\text { questionnaire score after receiving } \\
\text { glucagon - average autonomic score }\end{array}$} & $\mathrm{n}$ & 77 & 79 & 76 & 78 \\
\hline & Mean $\pm S D$ & $16.0 \pm 11.48$ & $14.2 \pm 9.40$ & $13.8 \pm 10.89$ & $12.0 \pm 7.44$ \\
\hline & $P$ value & & $0.241 \rrbracket$ & & $0.060 \ddagger$ \\
\hline \multirow{3}{*}{$\begin{array}{l}\text { Time (min) to minimum hypoglycemia } \\
\text { questionnaire score after receiving } \\
\text { glucagon - average neuroglycopenic } \\
\text { score }\end{array}$} & $\mathrm{n}$ & 77 & 79 & 76 & 78 \\
\hline & Mean $\pm S D$ & $16.7 \pm 10.22$ & $14.3 \pm 8.97$ & $14.2 \pm 15.12$ & $12.2 \pm 8.85$ \\
\hline & $P$ value & & $0.107 \rrbracket$ & & $0.183 \ddagger$ \\
\hline \multirow{3}{*}{$\begin{array}{l}\text { Time (min) to minimum hypoglycemia } \\
\text { questionnaire score after receiving } \\
\text { glucagon - average total score }\end{array}$} & $\mathrm{n}$ & 77 & 79 & 76 & 78 \\
\hline & Mean $\pm S D$ & $19.8 \pm 11.69$ & $17.0 \pm 8.85$ & $18.6 \pm 19.51$ & $14.5 \pm 8.39$ \\
\hline & $P$ value & & $0.055 \rrbracket$ & & $0.048 \ddagger$ \\
\hline \multirow[t]{3}{*}{ Dose preparation time (s)‡ } & $\mathrm{n}$ & NR & NR & 76 & 78 \\
\hline & Mean $\pm S D$ & & & $27.3 \pm 19.66$ & $97.2 \pm 45.06$ \\
\hline & $P$ value & & & & $\begin{array}{l}\text { Period } 1:<0.0001 \S \\
\text { Period } 2:<0.0001 \S\end{array}$ \\
\hline
\end{tabular}

*Analysis is conducted for all randomized participants based on actual treatment received. XSGP-301 statistics are based on modified intent-to-treat population. XSGP-303 statistics are based on intent-to-treat population.

†Participants successfully recovered from induced hypoglycemia without other rescue therapy after the 30 min cut-off.

¥Mixed model was applied to compare difference in treatment groups accounting for period and sequence as covariates.

$\S N o n-n o r m a l i t y ~ w a s ~ o b s e r v e d$, and log transformation did not resolve. A non-parametric Kruskal-Wallis test was applied excluding other covariates and conducted for each of the treatment periods separately.

IHR of the two treatment groups was compared using the log-rank test.

GAl, glucagon autoinjector; GEK, glucagon emergency kit; NR, not reported.

\section{Overall efficacy}

Across both studies, the proportion of participants who achieved treatment efficacy was $98.7 \%$ in the GAI group and $100 \%$ in the GEK group. Each study comparison between groups met the prespecified non-inferiority margin (failure score + one-sided confidence bound;
0.075 for XSGP-301 and 0.022 for XSGP-303) (online supplemental table 2). Participants treated with GAI $(99.4 \%)$ had a plasma glucose $>70 \mathrm{mg} / \mathrm{dL}(3.9 \mathrm{mmol} / \mathrm{L})$ or neuroglycopenic symptom relief within $30 \mathrm{~min}$, which was comparable with GEK. From the time of glucagon administration, the median time to any increase in 
A

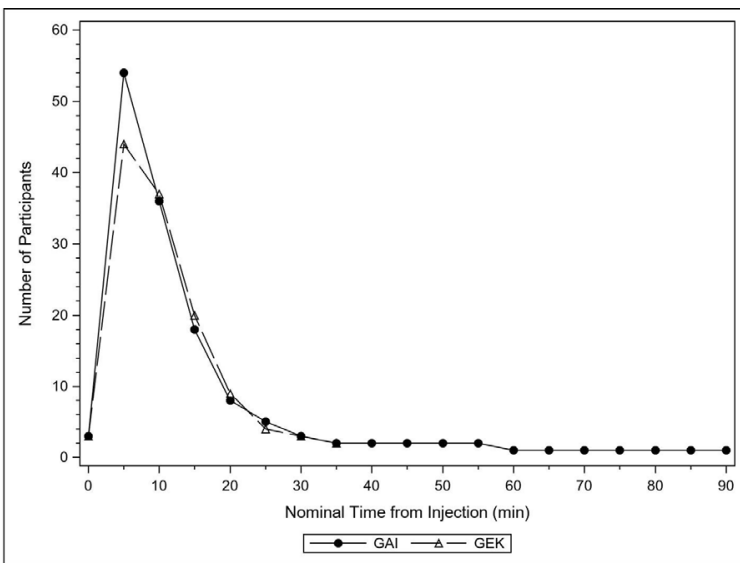

B

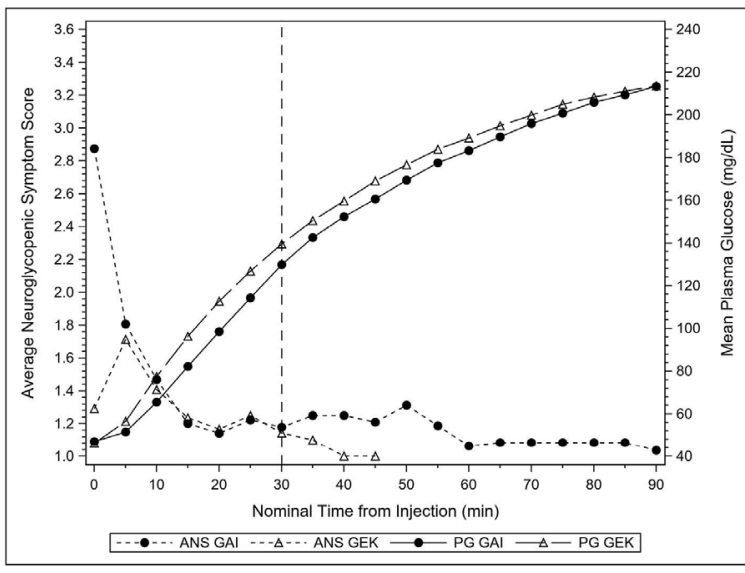

$\mathrm{C}$

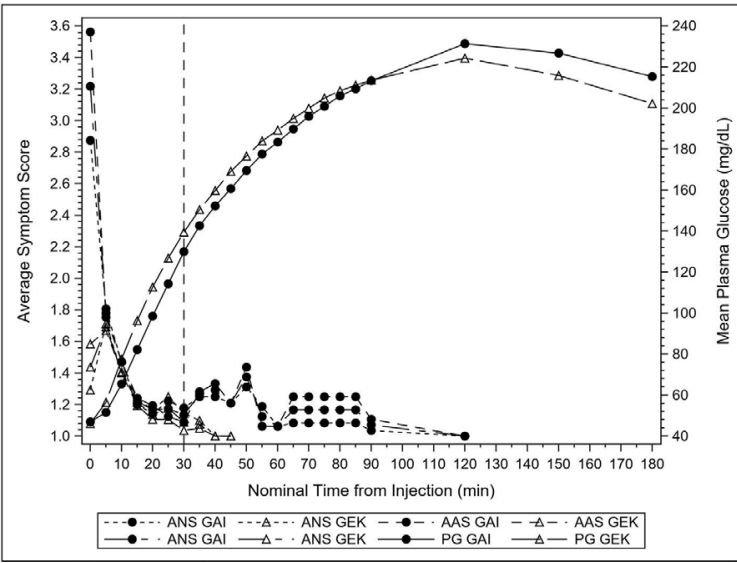

Figure 1 XSGP-303 - ITT population. (A) Number of participants with an average neuroglycopenic score $>1$ by nominal time from injection and treatment group; (B) mean neuroglycopenic symptom score and mean plasma glucose $(\mathrm{mg} / \mathrm{dL})$ by nominal time from injection and treatment group; and (C) mean hypoglycemia symptom score and mean plasma glucose $(\mathrm{mg} / \mathrm{dL})$ by nominal time from injection and treatment group. GAl, glucagon autoinjector; GEK, glucagon emergency kit; ITT, intent-to-treat.

plasma glucose with GAI was $102 \mathrm{~s}$, and the mean time to achieve plasma glucose $>70 \mathrm{mg} / \mathrm{dL}(3.9 \mathrm{mmol} / \mathrm{L})$ or increase in plasma glucose $\geq 20 \mathrm{mg} / \mathrm{dL}(1.1 \mathrm{mmol} / \mathrm{L})$ was $13.8 \pm 5.6 \mathrm{~min}$ for GAI and $10.0 \pm 3.6 \mathrm{~min}$ for GEK. This mean time does not account for time savings from the decision to dose, where there was a statistically significantly shorter drug preparation and administration
Table 3 Summary of treatment emergent adverse events occurring in at least two participants by treatment group safety population

\begin{tabular}{|c|c|c|}
\hline \multirow[b]{2}{*}{ Category } & \multicolumn{2}{|c|}{ Number of participants: $n(\%)$} \\
\hline & GAI (N=154) & GEK ( $N=157)$ \\
\hline $\begin{array}{l}\text { Any treatment emergent } \\
\text { adverse events }\end{array}$ & $71(46.1)$ & $52(33.1)$ \\
\hline \multicolumn{3}{|l|}{ Preferred term: } \\
\hline Diarrhea & $2(1.3)$ & $1(0.6)$ \\
\hline Nausea & $46(29.9)$ & 36 (22.9) \\
\hline Vomiting & $25(16.2)$ & $15(9.6)$ \\
\hline Injection site pain & $2(1.3)$ & $1(0.6)$ \\
\hline $\begin{array}{l}\text { Upper respiratory tract } \\
\text { infection }\end{array}$ & $2(1.3)$ & 0 \\
\hline Dizziness* & $2(1.3)$ & $1(0.6)$ \\
\hline Headache & $8(5.2)$ & $6(3.8)$ \\
\hline
\end{tabular}

Results presented have been pooled from both XSGP-301 and XSGP-303 and are presented by treatment.

Only preferred terms that resulted in two or more participants experiencing the event within the same treatment are included in this table.

Adverse events were coded using Medical Coding Dictionary for Regulatory Activities (MedDRA), V.20.0.

*Dizziness is coded under the system organ class 'nervous system disorders'.

GAl, glucagon autoinjector; GEK, glucagon emergency kit.

time for GAI $(27.3 \pm 19.7 \mathrm{~s})$ versus GEK $(97.2 \pm 45.1 \mathrm{~s})$ $((\mathrm{p}<0.0001)$ (table 2$)$ by trained healthcare providers.

\section{Overall safety and tolerability}

GAI and GEK were generally safe and well tolerated (table 3). The majority of treatment-emergent adverse events (TEAEs) were self-limited and completely resolved by the end of the study. The most common treatmentrelated AEs were nausea (29.9\% and $22.9 \%$ ), vomiting ( $16.2 \%$ and $9.6 \%)$, and headache $(3.2 \%$ each) for GAI and GEK, respectively. Injection site pain was reported by two participants with GAI and one participant with GEK. No other TEAEs occurred in more than one participant. With GAI, all TEAEs were mild or moderate, with no reported serious AEs. One participant in the GEK group experienced a serious and severe $\mathrm{AE}$ of hypoglycemia that was judged unrelated to study treatment. No participants discontinued due to an $\mathrm{AE}$, and no deaths were reported. No significant safety findings were reported. There were no remarkable differences in the incidence and severity of TEAEs between GAI-treated and GEKtreated participants.

\section{DISCUSSION}

Previous clinical studies with GAI demonstrated a PK profile for liquid stable glucagon that was conducive for treating severe hypoglycemia. ${ }^{16-18}$ Human factors studies with GAI and glucagon prefilled syringe established that $99 \%$ of users successfully and promptly delivered a full 
dose glucagon within a simulated emergency setting. ${ }^{8} 12$ The results from our studies demonstrate the efficacy and tolerability of GAI for treating severe hypoglycemia in patients with type 1 diabetes. GAI was non-inferior to GEK, achieved successful plasma glucose recovery within $30 \mathrm{~min}$, and was well tolerated with an incidence of nausea and vomiting comparable to GEK. All participants achieved successful rescue of hypoglycemia with a sustained return of normal plasma glucose levels and complete resolution of hypoglycemia symptoms using a single dose.

The prompt relief of neurologic symptoms is critical in the rescue of severe hypoglycemic emergencies because of the known risk of serious neurological complications. ${ }^{19}$ GAI achieved autonomic, neuroglycopenic, and total symptom relief during an episode of insulin-induced severe hypoglycemia. Resolution of hypoglycemia symptoms was similar between GAI and GEK groups. Time to resolution of autonomic and neuroglycopenic hypoglycemia symptoms did not differ significantly between GAI and GEK from either decision to dose or from time of administration of glucagon. In almost all cases, resolution of clinical symptoms preceded the return of documented euglycemia. Average hypoglycemia symptom scores were similar between GAI and GEK from 0 to $90 \mathrm{~min}$ post injection. Median time to a first response of 'No' to the question 'Do you currently feel hypoglycemic?' and median time to resolution of the aggregate hypoglycemia symptom scores were comparable for GAI and GEK. Average time to resolution of the global feeling of hypoglycemia did not differ significantly between GAI and GEK. Time to a first 'No' for the global question 'Do you currently feel hypoglycemic?' (ie, resolution of the global sensation of hypoglycemia) was significantly faster (2.5 min) for GAI compared with GEK from a decision to dose. Thus, any differences between GAI and GEK with respect to plasma PD glucose parameters, including mean time to plasma glucose $>70 \mathrm{mg} / \mathrm{dL}(3.9 \mathrm{mmol} / \mathrm{L})$, had no effect on resolution of symptoms. This is an important consideration, where restoration of neurologic function and oral intake is critical to further medically manage severe hypoglycemia.

GAI required significantly less preparation time than GEK. This finding has important ramifications during real-world use of the product by caregivers of PWD who would likely need even more time to prepare GEK than trained healthcare providers in these studies. Additionally, the manual reconstitution of powder glucagon and dose preparation in GEK is error prone, where less than $13 \%$ of caregivers can successfully prepare and administer a full dose of drug. ${ }^{5}$ Human factors studies with GAI demonstrated that $99 \%$ of users-adolescent and adult, trained and untrained-successfully prepared and promptly administered a full dose of glucagon on first attempt in a simulated emergency setting. ${ }^{8}$ The high functional efficacy (ability to successfully and promptly deliver a full dose of drug) in combination with significantly faster preparation time with GAI may be advantageous for PWD and caregivers when used in real-world emergency settings.

All TEAEs observed with GAI were mild or moderate in severity and typical of TEAEs reported from other studies of glucagon products for treating severe hypoglycemia. Nausea and vomiting were most common. ${ }^{20-22}$ No related serious AEs, deaths, or discontinuations for AEs were reported with GAI in these studies.

A potential limitation of these studies was that XSGP303 was single blind; however, owing to the objective nature of clinical and PD assessments, this was unlikely to have an impact on plasma glucose PD, AEs, and overall findings. XSGP-301 was double blind, and the findings were consistent between each study. Both studies used insulin-induced hypoglycemia clamp procedures to elicit level 2 hypoglycemia, in order to evaluate the efficacy of GAI, rather than actual episodes of hypoglycemia in those with type 1 diabetes. However, it would be unethical to elicit level 3 hypoglycemia and treat actual episodes of severe hypoglycemia because of the risk of serious consequences and the unpredictability of assessments in a rapidly evolving clinical emergency. The use of a crossover design, evaluation of objective endpoints, and the hypoglycemia questionnaire showed consistent findings both within and between studies.

The results of these two clinical studies demonstrate that ready-to-use GAI is a viable alternative to GEK and that GAI provides PWD and caregivers a ready-to-use delivery method that supports the prompt and reliable administration of a full dose of glucagon for emergency treatment of severe hypoglycemia.

Acknowledgements We would like to thank XSGP-301 investigators Mark P Christiansen, MD; Leslie Klaff, MD; Ronnie Aronson, MD; Robert Peters, PhD, MD; Fernando Ovalle, MD; Timothy Baily, MD; and Douglas Denham, MD; and XSGP-303 investigators: Mark Christiansen, MD; Robert Peters, PhD, MD; Ronnie Aronson, MD; Leslie Klaff, MD; Bruce Bode, MD, and Eric Sicard, MD. A special thank you and appreciation to all study participants. The authors would like to acknowledge the editorial assistance of Richard S Perry, PharmD, in the development of this manuscript, which was supported by Xeris Pharmaceuticals, Inc, Chicago, Illinois USA. A special thank you to James G Moore, MS, for poststudy statistical support and review of the manuscript.

Contributors MPC: contributed to design, acquisition, analysis and interpretation, manuscript preparations, review, and approval. MC: contributed to design, acquisition, analysis and interpretation, manuscript preparations, review, and approval. SP: contributed to design, acquisition, analysis and interpretation, manuscript preparations, review, and approval. AN and KJ: contributed to design, acquisition, analysis and interpretation, manuscript preparations, review, and approval. NCC: contributed to statistical analysis and interpretation, manuscript preparations, review, and approval.

Funding This study was funded by Xeris Pharmaceuticals, Chicago, Illinois, USA

Competing interests MPC is employed by Diablo Clinical Research, Walnut Creek, California, and served as a study investigator to Xeris Pharmaceuticals for both XSGP-301 and XSGP-303. As an employee of Diablo Clinical Research, MPC also receives research funding from Abbott Diabetes Care, Biolinq, Dexcom, Medtronic, Novo Nordisk, Eli Lilly, Helixmith, Pfizer, Novabio, GraphWear, Ascensia, Abbott Point of Care. MC was employed by Xeris Pharmaceuticals, Inc at the time of study conduct and analysis and currently serves as a consultant to Xeris Pharmaceuticals, Inc. SP and KJ are employees of Xeris Pharmaceuticals, Inc. AN is a former employee of Xeris Pharmaceuticals, Inc. NCC is employed by Empiristat, Inc and served as a consultant to Xeris Pharmaceuticals during the conduct of the study, study analysis, and manuscript development. 
Patient consent for publication Not required.

Ethics approval This study was conducted in accordance with the ethical principles of Good Clinical Practice and in accordance with the Declaration of Helsinki and current US Food and Drug Administration regulations. The study protocols and any amendments and informed consent forms were submitted to an Institutional Review board for review and approval. Written informed consent was obtained from a parent/guardian and assent was obtained from the participant before any study activities were performed.

Provenance and peer review Not commissioned; externally peer reviewed.

Data availability statement Data are available upon reasonable request. All data relevant to the study are included in the article or uploaded as supplementary information.

Supplemental material This content has been supplied by the author(s). It has not been vetted by BMJ Publishing Group Limited (BMJ) and may not have been peer-reviewed. Any opinions or recommendations discussed are solely those of the author(s) and are not endorsed by BMJ. BMJ disclaims all liability and responsibility arising from any reliance placed on the content. Where the content includes any translated material, BMJ does not warrant the accuracy and reliability of the translations (including but not limited to local regulations, clinical guidelines, terminology, drug names and drug dosages), and is not responsible for any error and/or omissions arising from translation and adaptation or otherwise.

Open access This is an open access article distributed in accordance with the Creative Commons Attribution Non Commercial (CC BY-NC 4.0) license, which permits others to distribute, remix, adapt, build upon this work non-commercially, and license their derivative works on different terms, provided the original work is properly cited, appropriate credit is given, any changes made indicated, and the use is non-commercial. See: http://creativecommons.org/licenses/by-nc/4.0/.

ORCID iD

Khaled Junaidi http://orcid.org/0000-0003-0581-5412

\section{REFERENCES}

1 Leese GP, Wang J, Broomhall J, et al. Frequency of severe hypoglycemia requiring emergency treatment in type 1 and type 2 diabetes: a population-based study of health service resource use. Diabetes Care 2003;26:1176-80.

2 American Diabetes Association. Standards of medical care in diabetes - 2020. Diabetes Care 2021;44:S73-84.

3 Kedia N. Treatment of severe diabetic hypoglycemia with glucagon: an underutilized therapeutic approach. Diabetes Metab Syndr Obes 2011:4:337-46.

4 Rylander D. Treating severe hypoglycemia: rapid mixing of lyophilized glucagon and diluent at point of care with the Enject GlucaPen. J Diabetes Sci Technol 2015;9:34-7.

5 Yale J-F, Dulude H, Egeth M, et al. Faster use and fewer failures with needle-free nasal glucagon versus injectable glucagon in severe hypoglycemia rescue: a simulation study. Diabetes Technol Ther 2017;19:423-32.

6 Ching K, Andre A, Crick M, et al. Biodel's glucagon emergency management auto reconstitution device demonstrates superior usability compared to market glucagon kits in human factors study. 15th Annual Meeting of the Diabetes Technology Society; October 22-24, Bethesda, MD, 2015:A15.

7 Settles JA, Gerety GF, Spaepen E, et al. Nasal glucagon delivery is more successful than injectable delivery: a simulated severe hypoglycemia rescue. Endocr Pract 2020;26:407-15.

8 Valentine V, Newswanger B, Prestrelski S, et al. Human factors usability and validation studies of a glucagon autoinjector in a simulated severe hypoglycemia rescue situation. Diabetes Technol Ther 2019;21:522-30.

9 Mitchell BD, He X, Sturdy IM, et al. Glucagon prescription patterns in patients with either type 1 or 2 diabetes with newly prescribed insulin. Endocr Pract 2016;22:123-35.

10 Newswanger B, Ammons S, Phadnis N, et al. Development of a highly stable, nonaqueous glucagon formulation for delivery via infusion pump systems. J Diabetes Sci Technol 2015;9:24-33.

11 Gvoke $($. Gvoke $₫$ package insert, 2019. Available: https://www. gvokeglucagon.com/pdf/gvoke-prescribing-information.pdf

12 Newswanger B, Prestrelski S, Andre AD. Human factors studies of a prefilled syringe with stable liquid glucagon in a simulated severe hypoglycemia rescue situation. Expert Opin Drug Deliv 2019;16:1015-25.

13 Draize JH, Woodard G, Calvery HO. Methods for the study of irritation and toxicity of substances applied topically to the skin and mucous membranes. J Pharmacol Exp Ther 1944;82:377-90.

14 Gold AE, MacLeod KM, Frier BM. Frequency of severe hypoglycemia in patients with type I diabetes with impaired awareness of hypoglycemia. Diabetes Care 1994;17:697-703.

$15 \mathrm{R}$ Core Team. R: a language and environment for statistical computing. Vienna, Austria: R Foundation for Statistical Computing, 2020. https://www.R-project.org/

16 Castle JR, Youssef JE, Branigan D, et al. Comparative pharmacokinetic/pharmacodynamic study of liquid stable glucagon versus lyophilized glucagon in type 1 diabetes subjects. J Diabetes Sci Technol 2016;10:1101-7.

17 Haymond MW, DuBose SN, Rickels MR, et al. Efficacy and safety of mini-dose glucagon for treatment of nonsevere hypoglycemia in adults with type 1 diabetes. J Clin Endocrinol Metab 2017;102:2994-3001.

18 Haymond MW, Redondo MJ, McKay S, et al. Nonaqueous, mini-dose glucagon for treatment of mild hypoglycemia in adults with type 1 diabetes: a dose-seeking study. Diabetes Care 2016;39:465-8

19 Briscoe VJ, Davis SN. Hypoglycemia in type 1 and type 2 diabetes: physiology, pathophysiology, and management. Clinical Diabetes 2006;24:115-21.

20 Hövelmann U, Bysted BV, Mouritzen U, et al. Pharmacokinetic and pharmacodynamic characteristics of dasiglucagon, a novel soluble and stable glucagon analog. Diabetes Care 2018;41:531-7.

21 Rickels MR, Ruedy KJ, Foster NC, et al. Intranasal glucagon for treatment of insulin-induced hypoglycemia in adults with type 1 diabetes: a randomized crossover Noninferiority study. Diabetes Care 2016;39:264-70.

22 Sherr JL, Ruedy KJ, Foster NC. T1D exchange intranasal glucagon Investigators. glucagon nasal powder: a promising alternative to intramuscular glucagon in youth with type 1 diabetes. Diabetes Care 2016;39:555-62. 